\title{
First record of Pyricularia grisea causing leaf blight of Costus spiralis in Brazil
}

\author{
Eduardo A. Santana • Eduardo Guatimosim • \\ Cicero A. G. Fuga • Chirlei Glienke • \\ Robert Weingart Barreto
}

Received: 29 April 2011 / Accepted: 16 May 2011 /Published online: 25 May 2011

(C) Australasian Plant Pathology Society Inc. 2011

\begin{abstract}
A leaf blight was observed on Costus spiralis in an experimental area in the campus of the Universidade Federal de Viçosa, Viçosa, Minas Gerais, Brazil. Morphology and ITS sequences placed the fungus associated with the disease in Pyricularia grisea. Pathogenicity was demonstrated. This is the first record of $P$. grisea on Costus spiralis worldwide.
\end{abstract}

Keywords Costaceae $\cdot$ Hyphomycete $\cdot$ Leaf-spot .

Magnapothe $\cdot$ Ornamental plant

Costus spiralis (Costaceae) - popular name in Brazil canade-macaco - is a tall herbaceous plant, native from South America, inclusive in Brazil. It is commonly used as an ornamental in shaded urban situations for its foliage and exotic inflorescences (Lorenzi and Souza 1995). Little has been published about fungi occurring on this host. Recently (July 2010), groups of plants of $C$. spiralis cultivated in an experimental area in the campus of the Universidade Federal de Viçosa were found to bear leaf spots that developed into damaging blight of the foliage. A hyphomycete was regularly found associated with the diseased tissues. Upon microscopic examination this was readily recognized as belonging to the genus Pyricularia (Ellis 1971).

E. A. Santana $\cdot$ E. Guatimosim • C. A. G. Fuga ·

R. W. Barreto $(\bowtie)$

Departamento de Fitopatologia, Universidade Federal de Viçosa, 36570-000 Viçosa, MG, Brazil

e-mail: rbarreto@ufv.br

C. Glienke

Departamento de Genética, Universidade Federal do Paraná,

CX Postal 19071 Jd. Américas,

81531-990 Curitiba, PR, Brazil
Representative samples were collected, dried in a plant press and deposited in the herbarium of the Universidade Federal de Viçosa (Herbarium VIC) under the accession number VIC 31595. The fungus was isolated in pure culture by direct transfer of conidia from sporulating lesions with a sterile fine pointed needle onto V8 juiceagar plates. Two isolates were selected and deposited in the CPC collection (working collection Pedro Crous, housed at the CBS-Netherlands), as CPC 18717 and CPC 18572. Slides containing fungal structures scraped from leaf surfaces with a scalpel or sections which were mounted in lactophenol or lactofuccsin were prepared. Morphology was studied with an Olympus BX 51 light microscope fitted with a drawing tube and an Olympus E330 camera and illustrations were prepared. ITS sequences of the fungus were generated and both morphology and sequences of the two isolates were found to perfectly
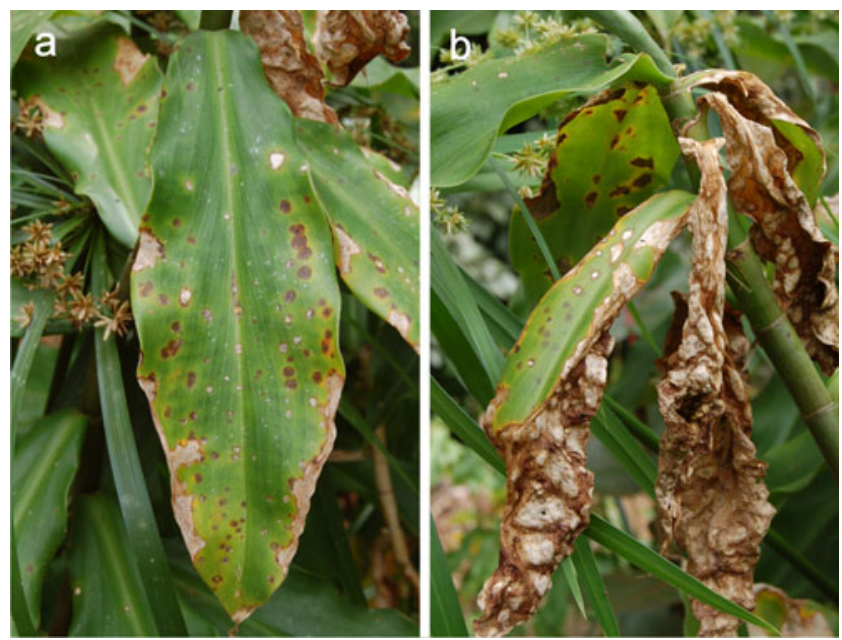

Fig. 1 Costus spiralis infected by Pyricularia grisea: initial stages of disease development (a); later stages (b) 


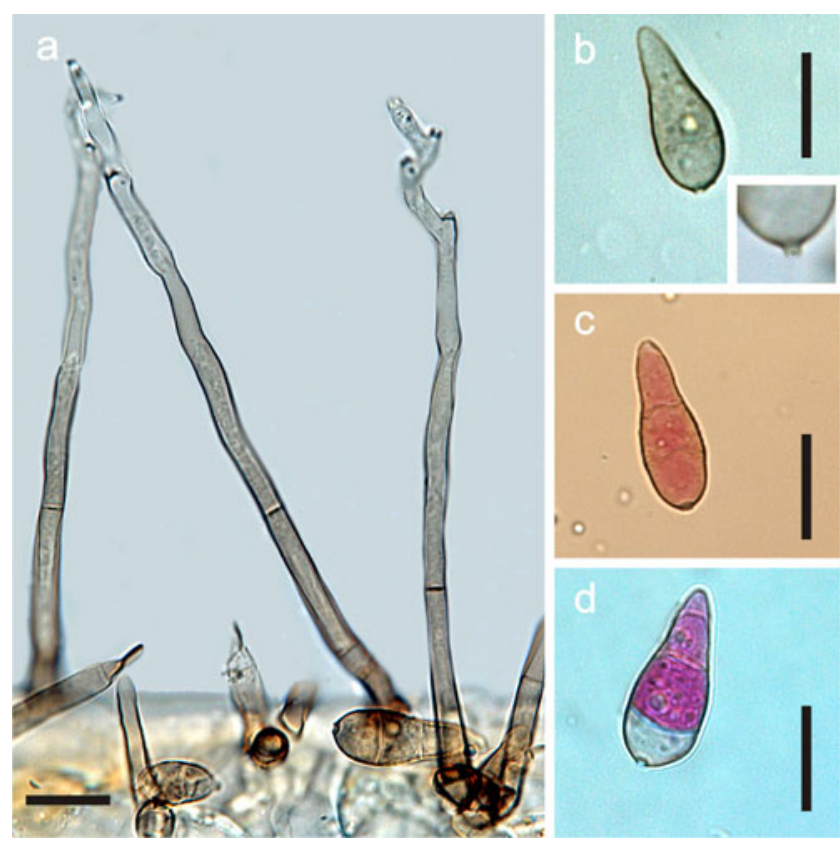

Fig. 2 Pyricularia grisea structures formed on Costus spiralis: conidiophores arising through stoma (a); conidia - note detail of hillum and variations of conidial shape $(\mathbf{b}-\mathbf{d})$. Bars $=10.0 \mu \mathrm{m}$

match. One sequence was deposited in GenBank (JF900343). Additionally inoculations of healthy $C$. spiralis individuals were carried out by spraying leaves until runoff with a $5.2 \times 10^{5}$ conidia/mL suspension to determine the pathological status of the fungus and involved inoculation of a total of 66 leaves of 3 plants cultivated in pots and kept in a greenhouse. Eight leaves were injured by prickling selected areas with a sterile needle prior to inoculation and 58 leaves were left intact when inoculated. All the plants were left in a moist
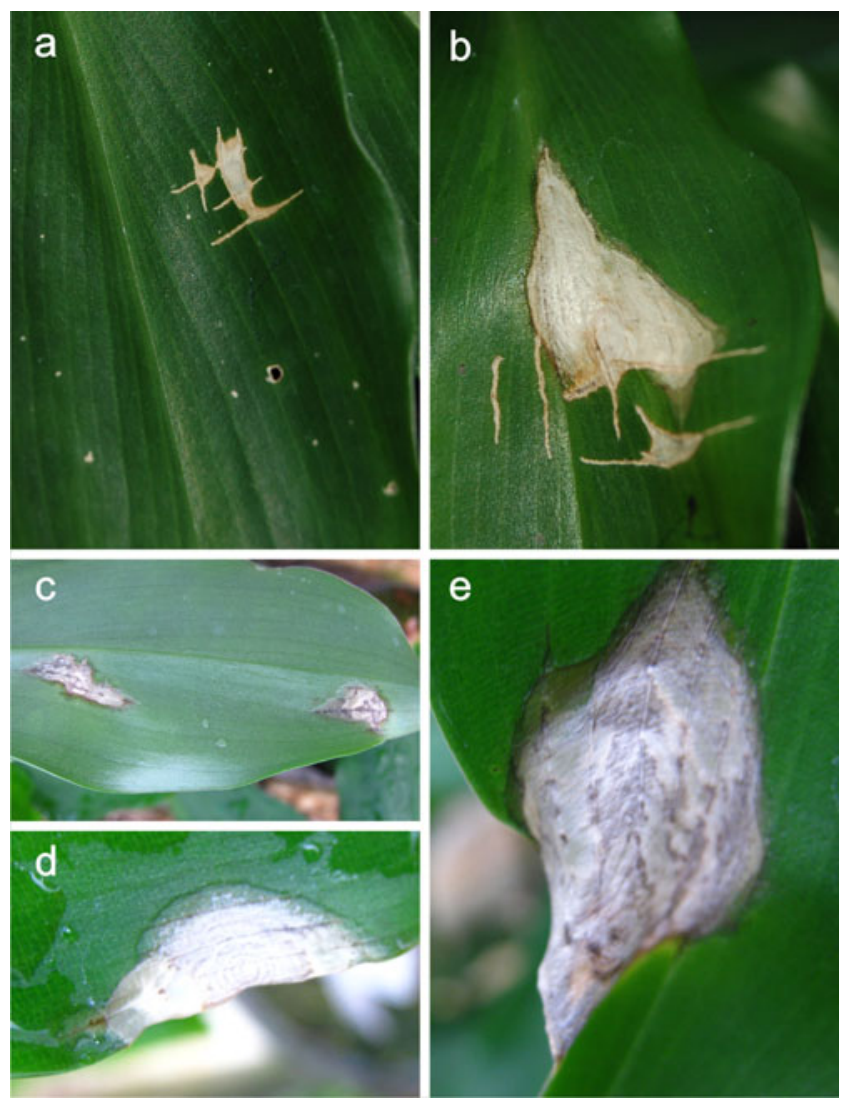

Fig. 4 Results of inoculations of Pyricularia grisea on Costus spiralis under controlled conditions: tests performed with wounds: negative control-injury only, after 13 days (a); injury and inoculation, after 13 days (b); inoculation only after 35 days (c-e)

chamber for $48 \mathrm{~h}$ after inoculation and taken to a greenhouse after this period. Evaluations (symptom observations) were performed daily, until the 13th day after the

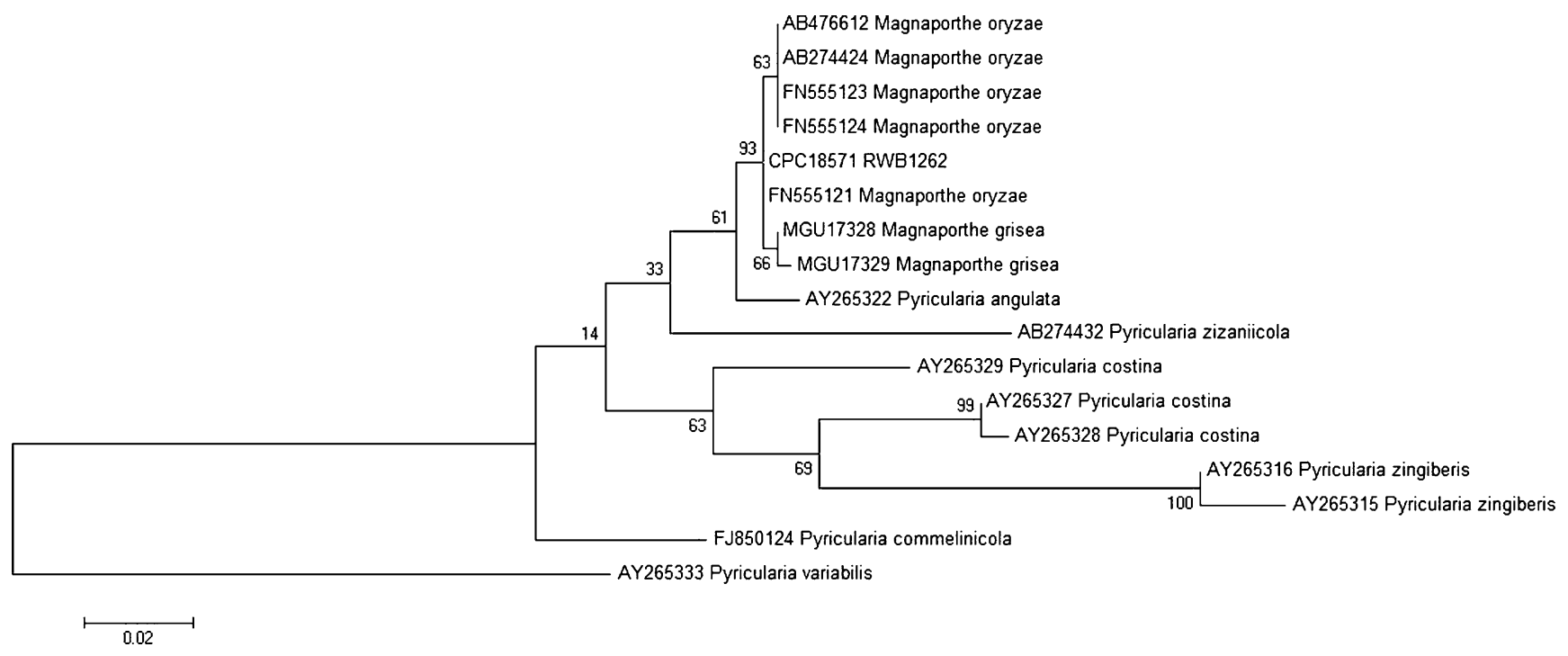

Fig. 3 Phylogenetic tree of the ITS sequence alignment. The scale bar shows 0.02 changes, and bootstrap support values from 1,000 replicates are shown at the nodes. The tree was rooted to a sequence of Pyricularia variabilis 
inoculation (injured leaves) and until the 35th day after inoculation (intact leaves).

The disease, as observed in the field, affected only leaves and started as minute scattered necrotic dots which enlarged, became circular to elliptic and coalesced leading to blight of large areas or entire leaves (Fig. 1). Morphology of the fungus was equivalent to that known for Pyricularia grisea and Pyricularia oryzae (Fig. 2) and was as follows: conidiophores hypophyllous, unbranched, cylindrical, mainly solitary denticulate, sympodial 60 $186 \times 4.5-6.5 \mu \mathrm{m}, 1-2$ septate, pale brown, and smooth; conidia obpyriform, with a protuberant hilum, 20.5-37× 10-13 $\mu \mathrm{m}, 2-$-septate, smooth, olivaceous brown.

The ITS sequence of the fungus on Costus was compared with that of 16 selected species of Pyricularia available in GenBank and phylogenetic analyses of the aligned sequence data were performed with MEGA 5.04 (Tamura et al. 2011). A Maximum Likelihood tree is presented (Fig. 3) clearly clustering the isolate from $C$. spiralis with both Magnaporthe grisea and Magnaporthe oryzae isolates and well separated from the species described from members of the Costaceae and Zingiberaceae. These two taxa are treated as a single species Magnaporthe grisea (anamorph P. grisea) (Rossman et al. 1990) or as two separate species M. grisea and M. oryzae (anamoprh Pyricularia oryzae) (Couch and Kohn 2002) depending on the authors. Authors regarding P. oryzae as a distinct species consider this as the agent involved in rice blast and also attacking some other grass species and P. grisea as being a more broad-spectrum species that attacks grasses and plants in other families. The subject is still controversial and remains to be resolved in phylogeny investigation works that are currently under way. For the moment, as the fungus under investigation was not collected on a grass, but on a member of the family Costaceae, we preferred to use the name $P$. grisea.

Pathogenicity of $P$. grisea to $C$. spiralis was demonstrated. Wounded leaves showed symptoms 13 days after inoculation whereas non-wounded leaves became blighted only 35 days after inoculation (Fig. 4). Only P. grisea was isolated from diseased tissue.
Three species of Pyricularia have been recorded on a single species belonging to the Costaceae (Costus speciosus) namely: $P$. costi from Taiwan (Tanaka 1920), P. costina from India (Sarbajna 1990) and P. grisea in Myanmar (Thaung 2008). Only two fungi were recorded in association with $C$. spiralis in Brazil: Alternaria tenuissima and Cochliobolus cynodontis (Mendes and Urben 2011). This is the first record of $P$. grisea causing leaf blight of $C$. spiralis in Brazil and worldwide.

Acknowledgements The authors would like to thank Coordenação de Aperfeiçoamento de Pessoal de Nível Superior (CAPES), Conselho Nacional de Desenvolvimento Científico e Tecnológico (CNPq) and Fundação de Amparao à Pesquisa do Estado de Minas Gerais (FAPEMIG) for financial support, and the CBS (Centraalbureau voor Schimmelcultures) for use of the facilities.

\section{References}

Couch BC, Kohn LM (2002) A multilocus gene genealogy concordant with host preference indicates segregation of a new species, Magnaporthe oryzae, from M. Grisea. Mycologia 94:683-693

Ellis MB (1971) Dematiaceous hyphomycetes. Commonwealth Mycological Institute, Kew

Lorenzi H, Souza HM (1995) Plantas Ornamentais no Brasil. Plantarum, Nova Odessa

Mendes MAS, Urben AF (2011) Fungos relatados em plantas no Brasil. Embrapa Recursos Genéticos e Biotecnologia. http:// pragawall.cenargen.embrapa.br/aiqweb/michtml/fgbanco01.asp. Accessed 21 April 2011

Rossman AY, Howard RJ, Valent B (1990) Pyricularia grisea, the correct name for the rice blast disease fungus. Mycologia 82:509-512

Sarbajna KK (1990) New species of Mycovellosiella and Pyricularia from West Bengal. J Mycopathol Res 28:159-164

Tamura K, Peterson D, Peterson N, Stecher G, Nei M, Kumar S (2011) MEGA5: molecular evolutionary genetics analysis using maximum likelihood, evolutionary distance, and maximum parsimony methods. Mol Biol Evol (In Press)

Tanaka T (1920) New Japanese fungi. Notes and translations VIII. Mycologia 12:25-32

Thaung MM (2008) A list of hyphomycetes (and agonomycetes) in Burma. Australas Mycologist 27:149-172 